This template is provided to give authors a basic shell for preparing your manuscript for submittal to a meeting or event. Styles have been included to give you a basic idea of how your finalized paper will look before it is published. All manuscripts submitted will be extracted from this template and tagged into an XML format; standardized styles and fonts will be used when laying out the final manuscript. Links will be added to your manuscript for references, tables, and equations. Figures and tables should be placed directly after the first paragraph they are mentioned in. The content of your paper WILL NOT be changed.

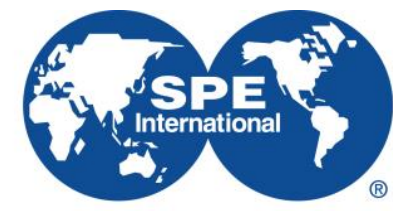

Society of Petroleum Engineers

\title{
SPE-186275-MS
}

\section{An Analytical Model for Multilayer Well Production Evaluation to Overcome Cross- Flow Problem}

Farizal Hakiki, King Abdullah Univesity of Science and Technology; Aris T. Wibowo, Pertamina EP; Silvya D. Rahmawati, Amega Yasutra, Pudjo Sukarno, Institut Teknologi Bandung

\section{Abstract}

One of the major concerns in a multi-layer system is that interlayer cross-flow may occur if reservoir fluids are produced from commingled layers that have unequal initial pressures. Reservoir would commonly have bigger average reservoir pressure (pore fluid pressure) as it goes deeper. The phenomenon is, however, not followed by the reservoir productivity or injectivity. The existence of reservoir with quite low average-pressure and high injectivity would tend experiencing the cross-flow problem. It is a phenomenon of fluid from bottom layer flowing into upper layer. It would strict upper-layer fluid to flow into wellbore. It is as if there is an injection treatment from bottom layer. The study deploys productivity index an approach parameter taking into account of cross-flow problem instead of injectivity index since it is a production well. The analytical study is to model the reservoir multilayer by addressing to avoid cross-flow problem. The analytical model employed hypothetical and real field data to test it. The scope of this study are: (a) Develop mathematical-based solution to determine the production rate from each layer; (b) Assess different scenarios to optimize production rate, those are: pump setting depth and performance of in-situ choke (ISC) installation. The ISC is acting as an inflow control device (ICD) alike that help to reduce cross-flow occurrence. This study employed macro program to write the code and develop the interface. Fast iterative procedure happens on solving the analytical model. Comparison results recognized that the mathematical-based solution shows a good agreement with the commercial software derived results.

Keywords: Multilayer reservoir; In-situ Choke; Inflow Control Valve; Inflow Control Device; Unequal pressures; Production optimisation.

\section{Introduction}

The frequently occurred problem in multilayer reservoir is crossflow. Term of crossflow may refer to two cases, those are: crossflow in reservoir formation (Park, 1989) and crossflow in wellbore (Jalalai et al., 2016). Crossflow in formation happens because each formation layer at interface is permeable which there 
exists distinct properties on each layer: porosity, vertical and horizontal permeability, saturation, rock compressibility, skin, productivity index (PI), and reservoir pressure (Happy et al., 2014). The properties allow the fluid to cross each layer reservoir. The study of formation crossflow could be evaluated by using flow well testing interpretation (Park, 1989; Happy et al., 2014) and temperature analysis of well (Mao and Zeidouni, 2017). Wellbore crossflow could happen once the production line is commingle and impermeable layer appears between the producing layers. This case may be called multilateral well (Permadi et al., 1998; Guo et al., 2008). Inter-wellbore crossflow could also be considered once multiwell are penetrating multilayer reservoir (Jalali et al. 2016).

The existence of crossflow triggers the engineer to invent some intelligent tools like in-flow control device (ICD), in-flow control valve (ICV), or choke-alike, at this paper, presented as in-situ choke (ISC). An evaluation of ICV application on horizontal well showed that evaluating pressure at junction and adjusting ICV at optimum pressure is critical (Zarea and Zhu, 2011). Therefore, an optimization study is needed prior to set the tool how many tool required is and perform wellbore segmentation (Ayesha et al. 2010).

Multilayer or multilateral well production evaluation study will be conducted through hypothetical field data. Cross flow situation is expected to occur during production time. This study will develop a multilayer well model and perform analytical calculation to determine cross flow situation. The model will consist composite reservoir IPR, choke model, and nodal analysis. The presence of ISC to handle cross-floww problem is studied over several setting depths. It is important to see the behavior of comingled layers under ISC installation.

The accurate evaluation is expected to give better understanding regarding multilayer production performance, cross flow condition and increasing current production rate. The aims of this paper are: 1. Develop mathematical-based solution to determine the production rate from each layer. 2. Assess different scenarios to optimise the production rate that is to design the ISC placement.

\section{Methods}

\subsection{Reservoir Model}

What a reservoir consists of seven layers was assumed in this study. Those are named from the most bottom as follow 1, 2, 3, 4, 5, 6, and 7. The character of reservoir should be inputted: average reservoir pressure, well PI, water cut, and layer depth. The considered fluid properties those are oil API, oil viscosity, brine density, and brine viscosity were gained from the arithmetic average of all layers.

Model development for this reservoir is assumed for liquid phase with known Productivity Index (PI) of well. Well PI model is given as follows (Brown, 1984; Guo et al., 2007).

$$
J_{i}=\frac{q_{i}}{{\overline{p_{r e s}}}_{i}-p_{w f_{i}}}
$$

Figure 1 depicts the flow compartment consists of three zones: 1 . The bottom layer(s) lies below the lowest packer, 2. Being sucked layer where suction pressure works and lies between two packers, and 3. The upper layer(s) lie above the highest packer. 


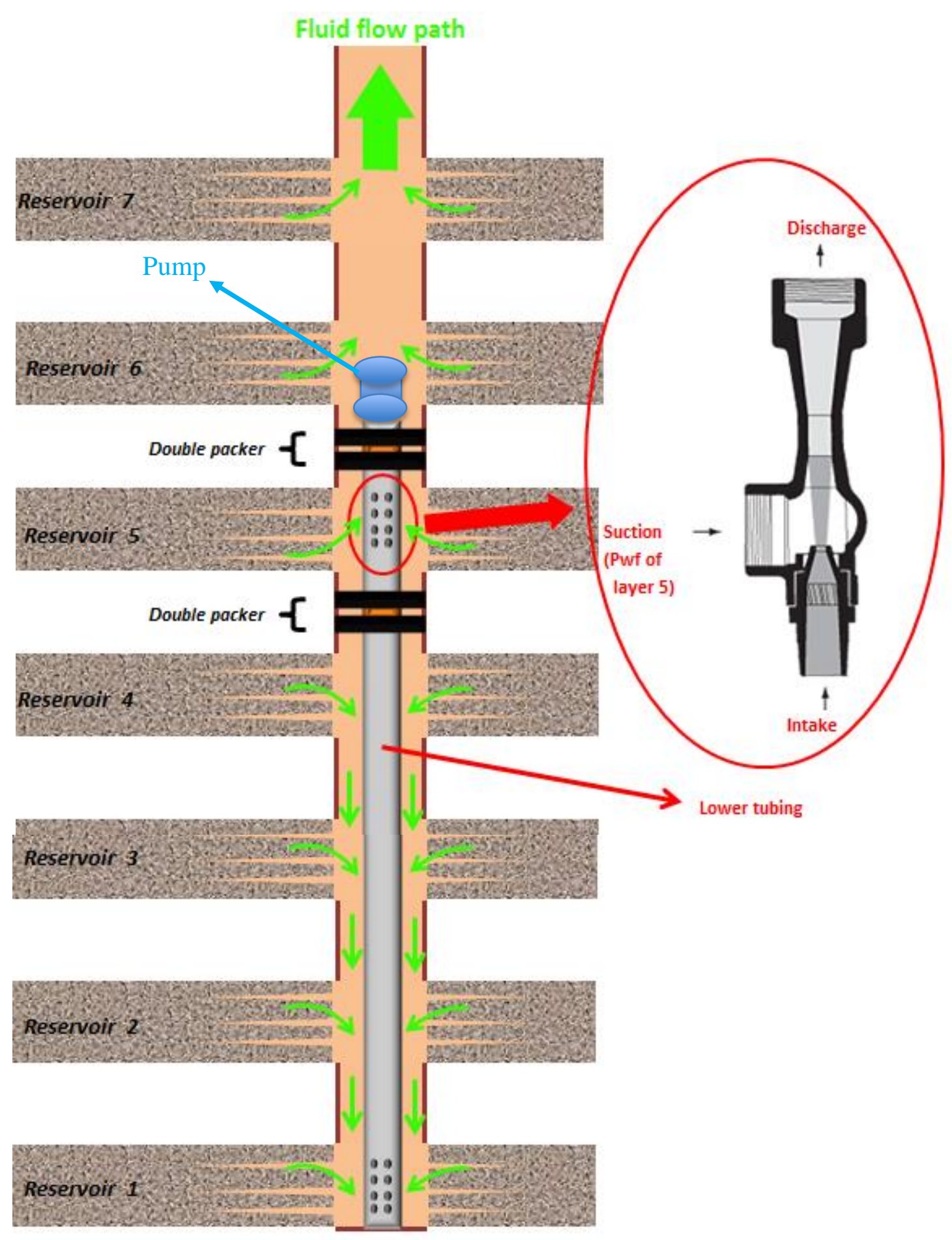

Figure 1. The entire illustration of the fluid flow in wellbore within tool.

Since the fluid flow path vertically goes down, this work attempts to consider the effect of the mass addition in every sand-face of layer hence the rate would be increased and, of course, it is followed by the existence of velocity (mass) cumulative term in Bernoulli's equation.

The sanity test algorithm is simplified to go straight upward and not being accumulated through the tubing. The concept is still same using Bernoulli because this law does not cover the path, only position (depth). Also, we do not include the friction effect. Term $p_{n}$ is defined as flowing bottom hole pressure $p_{w f_{i}} \equiv p_{i}$ at each layer sand-face ( $i$-th layer). 


$$
p_{n}-\overline{\left(\frac{\partial p}{\partial z}\right)} D_{n}+\frac{1}{2} \frac{\bar{\rho}}{g_{C}} \frac{1}{144}\left(\sum_{i=1}^{n} v_{i}\right)^{2}=p_{n+1}-\overline{\left(\frac{\partial p}{\partial z}\right)} D_{n+1}+\frac{1}{2} \frac{\bar{\rho}}{g_{C}} \frac{1}{144}\left(\sum_{i=1}^{n+1} v_{i}\right)^{2}
$$

The velocity is a function of rate and rate itself depends on the flowing well pressure. It, later, requires simultaneously solved equations to obtain well-flowing pressure $p_{i}$.

$$
v_{i}=\frac{q_{i}}{\frac{\pi}{4}\left(I D_{\text {cas }}^{2}-O D_{\text {tub }}^{2}\right)}=\frac{J_{i}\left({\overline{P_{\text {res }}}}_{i}-p_{i}\right)}{\frac{\pi}{4}\left(I D_{\text {cas }}^{2}-O D_{\text {tub }}^{2}\right)}, \quad i=1 \ldots n
$$

The bottom layer(s) which has higher pressure would act as a trigger zone as if it supplies power fluid for choke-modeled tool system. Suction pressure is defined as the lowest pressure due to outflow across nozzle-type orifice choke. Suction pressure would act as a bottom hole flowing pressure for layer where the tool is addressed. The intake fluid into tubing is on the bottom most layer position. The intake fluid into tool has the same position with the tool position. Fluid flow on the layer above the tool, called upper layer, also considers the effect of mass or velocity addition for each passing through the layer's sand-face.

\subsection{In-Situ Choke Model}

In-Situ Choke (ISC) works mechanically assisted by fluid within parallel venturi pipe system in order to create Venturi effect. The Venturi effect is the reduction in fluid pressure that results when a fluid flows through a constricted section of pipe. It is installed in wellbore to optimize fluid production from two reservoirs which have unequal reservoir pressure. Since there is a constricted section in pipe, it could be modelled as a nozzle-type choke combined with jet pump. The mathematical models of nozzle-type choke combined with jet pump is derived as follows (Guo et al., 2007).

$$
q=8074 C_{D} d_{2}^{2} \sqrt{\frac{\Delta p-\overline{\left(\frac{\partial p}{\partial z}\right)}}{\bar{\rho}}}
$$

Or equivalent with

$$
\Delta p=p_{\text {intake }}-p_{\text {suction }}=\frac{q^{2} \bar{\rho}}{\left(8074 C_{D} d_{2}^{2}\right)^{2}}
$$

Where

$$
\begin{gathered}
C_{D}=\frac{d_{2}}{d_{1}}+\frac{0.3167}{\left(\frac{d_{2}}{d_{1}}\right)^{0.6}}+0.025\left[\log N_{R e}-4\right] \\
N_{R e}=\frac{1.48 q \bar{\rho}}{d_{2} \bar{\mu}}
\end{gathered}
$$

Inlet pressure is a flowing bottom hole pressure existing on bottom grouped layer and outlet pressure exists on the upper layer. Substitution and combination among those equations above is presented below to do an iteration job. 


$$
q=8074\left\{\frac{d_{2}}{d_{1}}+\frac{0.3167}{\left(\frac{d_{2}}{d_{1}}\right)}+0.025\left[\log \left(\frac{1.48 q \bar{\rho}}{d_{2} \bar{\mu}}\right)-4\right]\right\} d_{2}^{2} \sqrt{\frac{p_{I N}-p_{\text {OUT }}}{\bar{\rho}}}
$$

Results of combinatorics method was later to use in knowing where the ISC should be placed. Those all equations and iteration jobs were computed into macro-excel program. It must be carefully done for inputting value on iteration calculation that flowing rate across the nozzle-type choke is only from the bottom layer. Explanation of "STEP 0", "STEP 1", "STEP 2" and related terms in work flow are detailed on Results and Discussion section (Also see Figure 2).

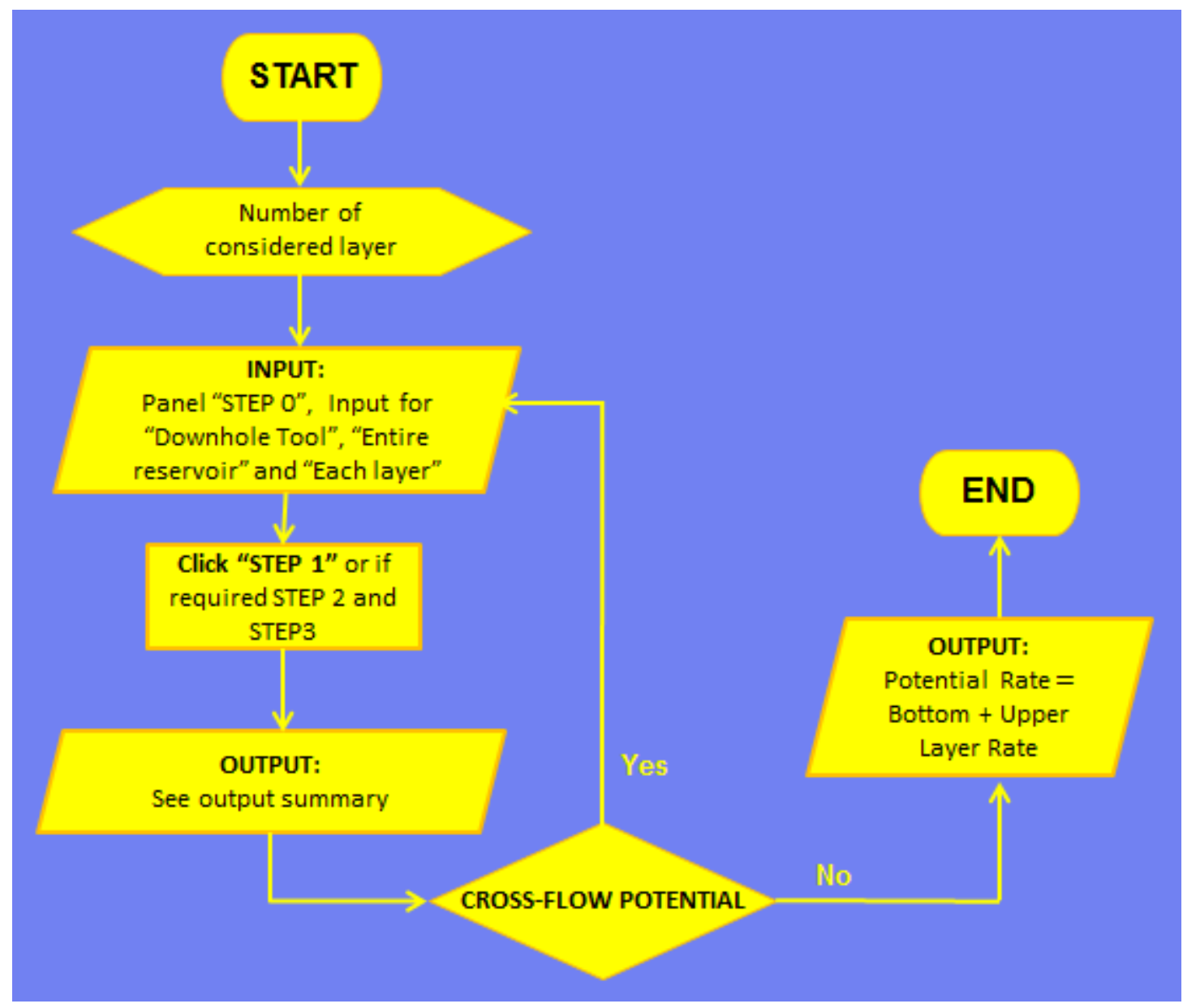

Figure 2. Work flow in using multilayer assessment program.

\section{Results and Discussion}

\subsection{Toolkit Development}

Computation and iteration job described in methodology has been coded into macro-excel program. The appearance of user's guide could be seen and reviewed in consecutive figures below (Figure 3 to Figure 10). The typical data we obtain about well are: Pump Setting Depth PSN, Submergent $S U B$, and Depth of Fluid Level DFL or some case we need to compute one of them as presented by Eq. 8. The effort is to obtain discharge pressure $P_{\text {disc }}$ which required to set the intake pressure $P_{\text {intake }}$ using engineering wise 5-100 psi pressure difference $\delta P$. We set the intake or discharge at particular pressure because we have installed a pump so it could work as required by ISC. 


$$
\begin{gathered}
D F L=P S N-S U B \\
P_{\text {disc }}=\overline{\left(\frac{\partial p}{\partial z}\right)}\left(D_{n}-L_{\text {tool }}-D F L\right) \\
P_{\text {intake }}=P_{\text {disc }}+\delta P
\end{gathered}
$$

\begin{tabular}{|c|c|c|}
\hline $\begin{array}{l}\text { Input for downh } \\
\text { STEP 0: Determine "Disch }\end{array}$ & $\begin{array}{l}\text { lole tool } \\
\text { arge Press }\end{array}$ & sure $\left(P_{2}\right) "$ \\
\hline Set to above layer & 1 (No tool) & - \\
\hline Nozzle ID & 0.44 & inch \\
\hline Guess suction pressure $\left(P_{3}\right)$ & 500 & psia \\
\hline Guess intake pressure $\left(P_{1}\right)$ & 540 & psia \\
\hline Tool length & 10 & $f t$ \\
\hline Lower tubing OD & 3.00 & inch \\
\hline Lower tubing ID & 2.44 & inch \\
\hline Discharge pressure $\left(P_{2}\right)$ & 533 & psia \\
\hline
\end{tabular}

\section{Input:}

Figure 3. The interface of tool properties.

To set the "Discharge pressure" click button "STEP 0".

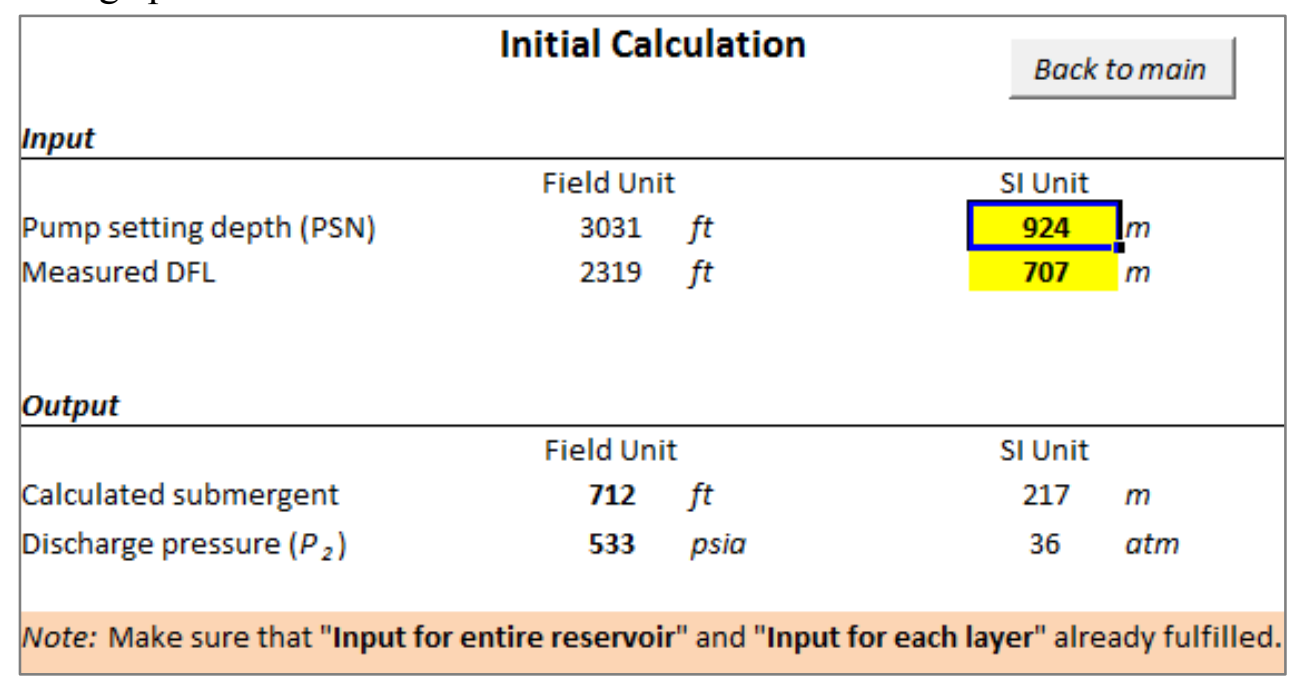

Figure 4. The interface of initial calculation to determine discharge pressure.

To know what the "Suction pressure", "Intake pressure" and "Discharge pressure" are, click "Illustration and Tutorial" on calculator panel. If the reservoir consists of a single layer, set discharge pressure, intake and suction pressure are equivalent. 


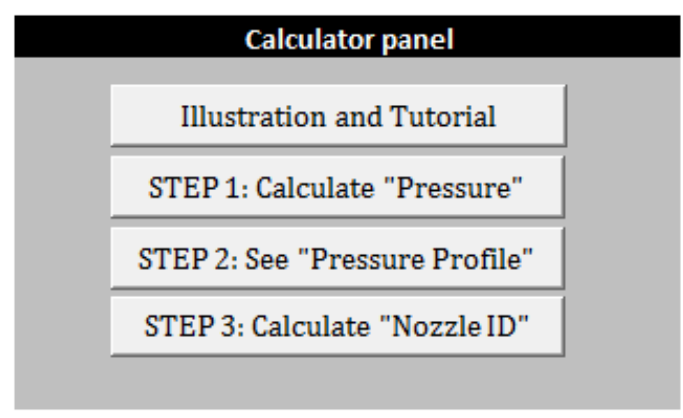

Figure 5. Calculator panel.

\begin{tabular}{|c|c|c|}
\hline \multicolumn{3}{|l|}{ Reservoir 3} \\
\hline P-res & & psia \\
\hline PI & & stb/psi/day \\
\hline Water cut & & $\%$ \\
\hline Depth & & $f t$ \\
\hline \multicolumn{3}{|l|}{ Reservoir 2} \\
\hline P-res & & psia \\
\hline PI & & stb/psi/day \\
\hline Water cut & & $\%$ \\
\hline Depth & & $f t$ \\
\hline \multicolumn{3}{|l|}{ Reservoir 1} \\
\hline P-res & 559.64 & psia \\
\hline $\mathrm{PI}$ & 1.01 & stb/psi/day \\
\hline Water cut & 96.76 & $\%$ \\
\hline Depth & 3543.31 & $f t$ \\
\hline
\end{tabular}

Figure 6. The input interface of each layer properties.

\begin{tabular}{lcl}
\hline \multicolumn{3}{c|}{ Input for entire reservoir } \\
\hline & & \\
Oil density & 40.15 & $\mathrm{API}$ \\
Oil viscosity & 1.25 & $\mathrm{CP}$ \\
Brine density & 1.02 & $\mathrm{~kg} / \mathrm{L}$ \\
Brine viscosity & 1.10 & $\mathrm{CP}$ \\
Casing ID & 7.00 & inch \\
\end{tabular}

Figure 7. The input interface of entire reservoir.

\section{Process:}

Click on calculator panel and make sure that the column "LHS-RHS" is zero after clicking "Calculate FBHP”. If not zero there must be problem that the user is required to change the tool depth position $L_{t o o l}$. 


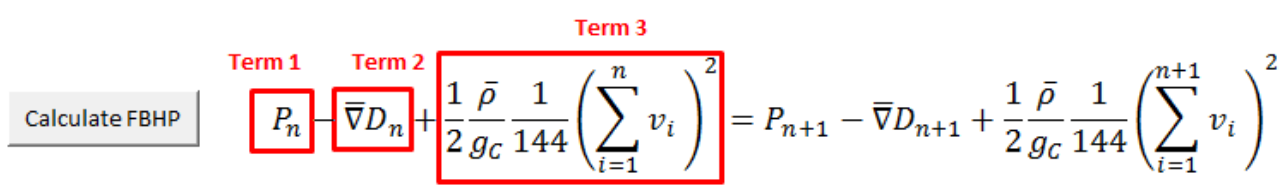

\begin{tabular}{|c|c|c|c|c|c|c|c|c|c|c|}
\hline t-sq & Lower tubing area & 0.0324 & $2 \mathrm{ft}-\mathrm{sq}$ & Casing area & $\mathrm{ft}-\mathrm{sq}$ & & & & & \\
\hline $\mathrm{m}^{*} \mathrm{ft} /\left(\mathrm{lbf}{ }^{*} \mathrm{~s}^{\wedge} 2\right)$ & Tool positiol & 1.00 & & & & Term 1 & Term 2 & Term 3 & & LHS-RHS \\
\hline sia & $q^{3}$ & $0 \mathrm{stb} / \mathrm{d}$ & V3 & $0 \mathrm{ft} / \mathrm{s}$ & $0.000000 \mathrm{ft} / \mathrm{s}$ & 533 & 0 & 0 & 533 & $0 E+00$ \\
\hline
\end{tabular}

Figure 8. Calculation on Flowing Bottom Hole Pressure (FBHP) panel.

By clicking the "STEP 2", the user could see the pressure profile if the reservoir consists of some layers. Hence, the user could assess the pump position should be addresses roughly. Term 1 means the absolute pressure contribution. Term 2 and 3 are the potential and kinetics pressure consecutively. The computation reveals that the effect of Term 3 is minute for almost all cases in which it could diminish this term.

By clicking "STEP 3", the user would determine "Nozzle ID" value on panel "Input for downhole tool". It is not really important since it is just technical calculation to make sure that the suction pressure and intake pressure inputted are theoretically correct. This value could be sot realistically incorrect based on the manufacturing availability that leads ignoring on the nozzle ID input. The suction pressure P3 and intake pressure P1 should not be too much different.

\section{Output:}

The output is given directly on output summary panel.

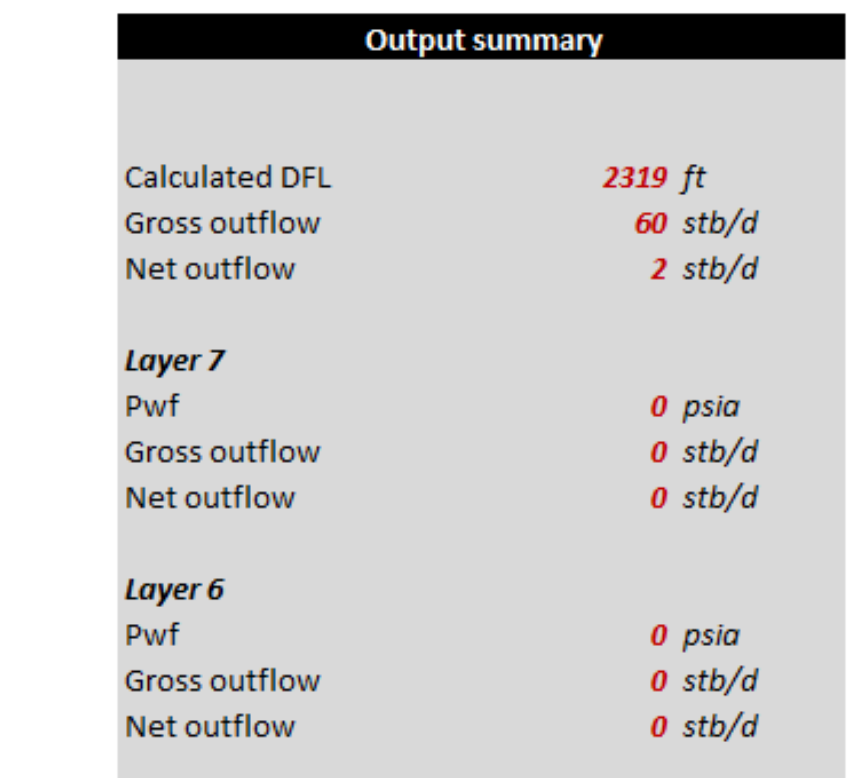

Figure 9. Output summary if the wellbore is not fully filled by liquid.

The cell "Calculated DFL" appears if the fluid could not flow without the assistance of pump or mathematically resulting in negative well pressure. If not, that cell appears as "Wellhead pressure" as an example as come up in Figure 10. 


\section{Output summary}

\begin{tabular}{|c|c|}
\hline Wellhead pressure & 449 psia \\
\hline Gross outflow & $60 \mathrm{stb} / \mathrm{d}$ \\
\hline Net outflow & $2 \mathrm{stb} / \mathrm{d}$ \\
\hline \multicolumn{2}{|l|}{ Layer 7} \\
\hline Pwf & 0 psia \\
\hline Gross outflow & 0 stb/d \\
\hline Net outflow & $0 \mathrm{stb} / \mathrm{d}$ \\
\hline \multicolumn{2}{|l|}{ Layer 6} \\
\hline Pwf & 0 psia \\
\hline Gross outflow & $0 \mathrm{stb} / d$ \\
\hline
\end{tabular}

\subsection{Algorithm Testing}

Assume there are five layers of reservoir and the user would do a variation on tool position described as in Figure 11 to Figure 14. Figure 11 to Figure 14 illustrate the Case \#2 to \#5 where the variation of tool position were performed. Case \#1 is a basic condition where no tool of ISC addressed. This test is to assess the algorithm of ISC to compute the contribution of bottom layer to the upper layer, determine the choke diameter, and see the cross flow possibility. The test is not including in the three areas of flow compartments; only bottom and upper where intake and discharge pressure works as portraid in Figure 1.

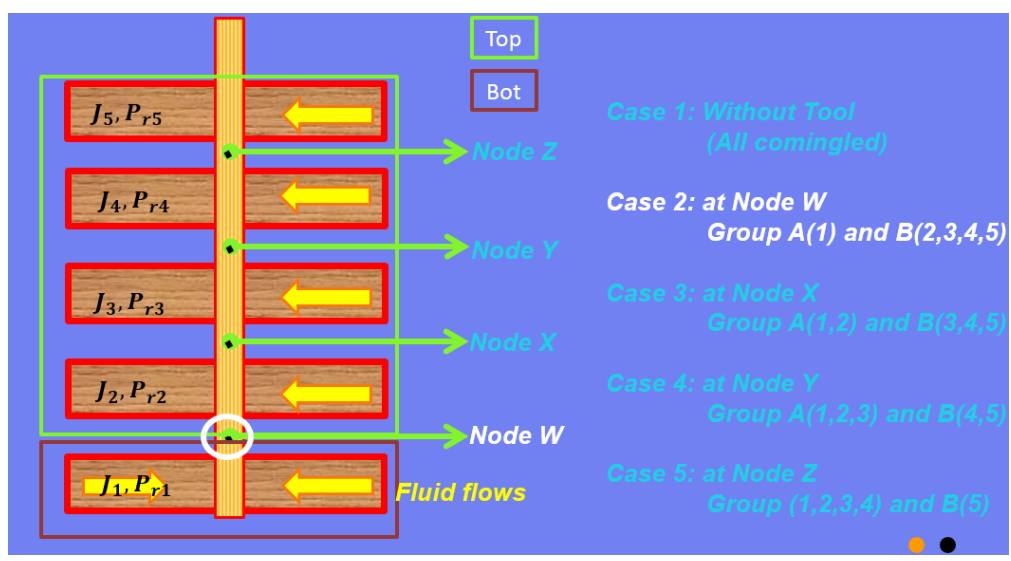

Figure 11. Illustration of case \#2 where ISC placed between bottom reservoir consists of layer 1 and upper reservoir consists of layer 2, 3, 4 and 5 . 


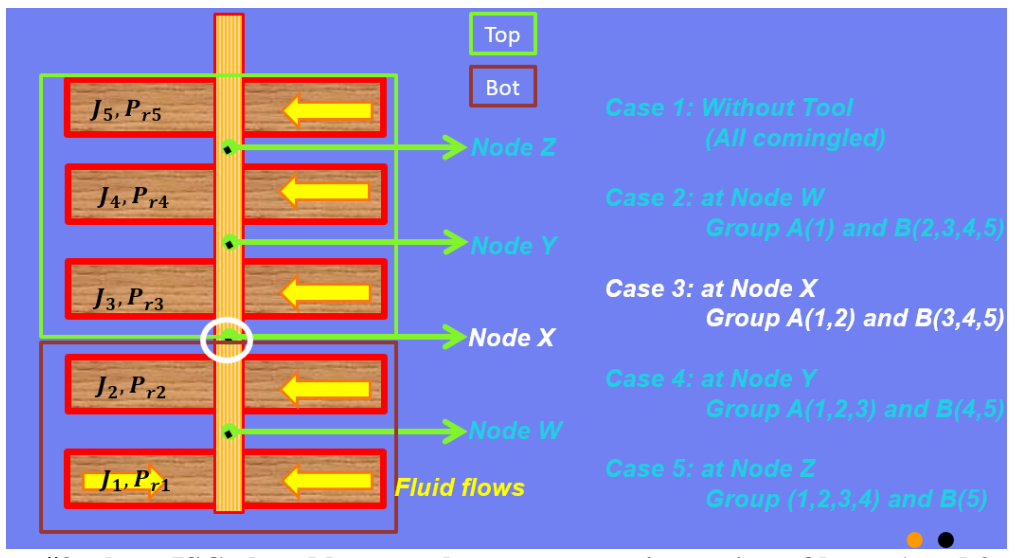

Figure 12. Illustration of case \#3 where ISC placed between bottom reservoir consists of layer 1 and 2 and upper reservoir consists of layer 3, 4 and 5 .

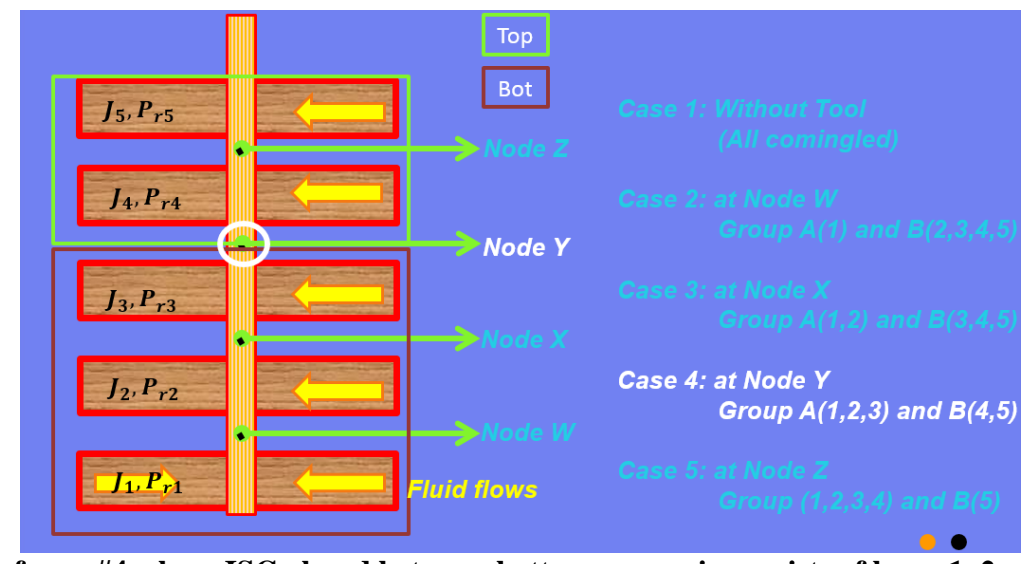

Figure 13. Illustration of case \#4 where ISC placed between bottom reservoir consists of layer 1, 2 and 3 and upper reservoir consists of layer 4 and 5.

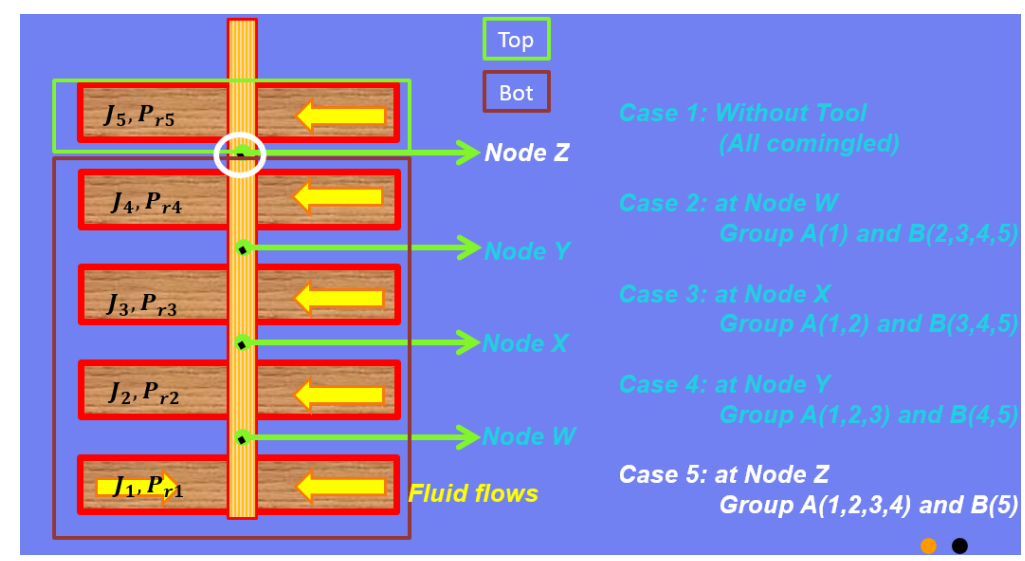

Figure 14. Illustration of case \#5 where ISC placed between bottom reservoir consists of layer 1, 2, 3 and 4 and upper reservoir consists of layer 5 .

Table 1 points out the computation of discharge pressure that would correspond to the deepest position of upper layers. Case \#5 shows that crossflow may happen at the lowest layer (layer 4) of upper layer group. It is shown by negative flow. Normal case without ISC has shown obvious results that layer 4 and 5 may encountered crossflow. The consideration of the best may look at the highest total rate or the pump ability of how deep it could be set. 
Table 1. Results of using analytical program to calculate upper flowing well pressure or discharge pressure. Tubing ID: 3 inch, API density: 45, Oil viscosity: $1.25 \mathrm{cP}$. The yellow cells indicate the values being computed, red one is the bottom layer(s), and the green is the upper layer(s).

\begin{tabular}{|c|c|c|c|c|c|c|c|c|c|}
\hline \multirow{2}{*}{$\begin{array}{c}\text { Case } \\
\#\end{array}$} & \multicolumn{2}{|c|}{$P_{w f}[\mathrm{psia}]$} & \multirow{2}{*}{$\begin{array}{c}\text { Choke } \\
\text { diameter } \\
\text { [inch] }\end{array}$} & \multirow{2}{*}{$\begin{array}{c}q_{1} \\
{[\mathrm{stb} / \mathrm{d}]}\end{array}$} & \multirow{2}{*}{$\begin{array}{c}q_{2} \\
{[\mathrm{stb} / \mathrm{d}]}\end{array}$} & \multirow{2}{*}{$\begin{array}{c}q_{3} \\
{[\mathrm{stb} / \mathrm{d}]}\end{array}$} & \multirow{2}{*}{$\begin{array}{c}q_{4} \\
{[\mathrm{stb} / \mathrm{d}]}\end{array}$} & \multirow{2}{*}{$\begin{array}{c}q_{5} \\
{[\mathrm{stb} / \mathrm{d}]}\end{array}$} & \multirow{2}{*}{$\begin{array}{l}\text { Total } \\
\text { rate } \\
{[\mathrm{stb} / \mathrm{d}]}\end{array}$} \\
\hline & $\begin{array}{c}\text { Intake } \\
\text { (Bottom) }\end{array}$ & $\begin{array}{c}\text { Dischare } \\
\text { (Upper) }\end{array}$ & & & & & & & \\
\hline 1 & 2605 & 2605 & N/A & 14450 & 3672 & 100 & -696 & -3757 & 13769 \\
\hline 2 & 2605 & 2127 & 0.75 & 14450 & 44533 & 48043 & 1716 & 2176 & 110918 \\
\hline 3 & 2605 & 1856 & 0.75 & 14450 & 3672 & 75147 & 3079 & 5530 & 101878 \\
\hline 4 & 2605 & 1848 & 0.75 & 14450 & 3672 & 100 & 3121 & 5632 & 26975 \\
\hline 5 & 2605 & 1904 & 0.75 & 14450 & 3672 & 100 & -696 & 4963 & 22462 \\
\hline
\end{tabular}

Case of handling for constant discharge pressure and to compute the ISC size arise in Table 2. The engineering wise is to use 100 psi pressure difference between intake and discharge pressure. A constant intake and discharge pressure should be made at the condition with no crossflow might occur. The size of ISC which could also be the size of ICV or ICD is subject to the wellbore, tubing size, or well architecture compatibility.

Table 2. Results of using analytical program to calculate choke size $d_{2}$. Tubing ID: 3 inch, API density: 45, Oil viscosity: 1.25 cP.

The yellow cells indicate the values being computed, red one is the bottom layer(s), and the green is the upper layer(s).

\begin{tabular}{|c|c|c|c|c|c|c|c|c|c|}
\hline \multirow{2}{*}{$\begin{array}{c}\text { Case } \\
\#\end{array}$} & \multicolumn{2}{|c|}{$P_{w f}[\mathrm{psia}]$} & \multirow{2}{*}{$\begin{array}{c}\text { Choke } \\
\text { diameter } \\
\text { [inch] }\end{array}$} & \multirow{2}{*}{$\begin{array}{c}q_{1} \\
{[\mathrm{stb} / \mathrm{d}]}\end{array}$} & \multirow{2}{*}{$\begin{array}{c}q_{2} \\
{[\mathrm{stb} / \mathrm{d}]}\end{array}$} & \multirow{2}{*}{$\begin{array}{c}q_{3} \\
{[\mathrm{stb} / \mathrm{d}]}\end{array}$} & \multirow{2}{*}{$\begin{array}{c}q_{4} \\
{[\mathrm{stb} / \mathrm{d}]}\end{array}$} & \multirow{2}{*}{$\begin{array}{c}q_{5} \\
{[\mathrm{stb} / \mathrm{d}]}\end{array}$} & \multirow{2}{*}{$\begin{array}{l}\text { Total } \\
\text { rate } \\
\text { [stb/d] }\end{array}$} \\
\hline & $\begin{array}{c}\text { Intake } \\
\text { (Bottom) }\end{array}$ & $\begin{array}{c}\text { Discharge } \\
\text { (Upper) }\end{array}$ & & & & & & & \\
\hline 1 & 2301 & 2301 & N/A & 24786 & 29634 & 30561 & 837 & 12 & 85830 \\
\hline 2 & 2301 & 2200 & 1.45 & 24786 & 38259 & 40681 & 1346 & 1265 & 106337 \\
\hline 3 & 2301 & 2200 & 2.05 & 24786 & 29634 & 40681 & 1346 & 1265 & 97711 \\
\hline 4 & 2301 & 2200 & 2.45 & 24786 & 29634 & 30561 & 1346 & 1265 & 87592 \\
\hline 5 & 2301 & 2200 & 2.46 & 24786 & 29634 & 30561 & 837 & 1265 & 87083 \\
\hline
\end{tabular}

The ultimate summary of the simulation is compared to the commercial software results as turned out in Table 3. The relative errors emerge that analytical formula executes with a good deal. The withdrawn knowledge is that the most influencing pressure in fluid flow through the pipe is the absolute pressure which confirms the flowing well pressure and the potential pressure due to depth or layer position. The contribution of kinetics pressure is negligible. 
Table 3. Comparative calculation between analytical program and commercial software. Tubing ID: 3 inch, Nozzle size: 0.75 inch, API density: 45, Oil viscosity: 1.25 cP, Intake pressure of tool: 2605 psia and Suction pressure is calculated.

\begin{tabular}{|c|c|c|c|}
\hline \multirow{2}{*}{ Case } & \multicolumn{2}{|c|}{$\begin{array}{l}\text { Net flow rate from all layers } \\
\qquad[\mathrm{stb} / \mathrm{d}]\end{array}$} & \multirow{2}{*}{$\begin{array}{l}\text { Relative error [ ] } \\
\frac{|X-Y|}{Y} \times 100 \%\end{array}$} \\
\hline & $\begin{array}{c}\text { Analytical } \\
\text { program, } X\end{array}$ & $\begin{array}{l}\text { Commercial } \\
\text { software, } Y\end{array}$ & \\
\hline 1 & 13769 & 12366 & 11.34 \\
\hline 2 & 110918 & 112546 & 1.45 \\
\hline 3 & 101878 & 101053 & 0.82 \\
\hline 4 & 26975 & 25873 & 4.23 \\
\hline 5 & 22462 & 21341 & 5.25 \\
\hline
\end{tabular}

\subsection{Hypothetic Data Validation}

The hypothetical data derived from finite-difference based reservoir simulator were abstracted to test the program. The comparison study was also conducted to know the difference of the program results with common software. The model on software was built with 5 reservoir layers with the same properties as well as data used in developed toolkit.

The pressure data obtained from the simulator are initially 1779 psia at $3609 \mathrm{ft}, 1725 \mathrm{psia}$ at $3281 \mathrm{ft}$, and 2122 psia at $2625 \mathrm{ft}$ for layer 1,2, and 3 respectively. They are yet to adjust to the current condition and the datum depth that is layer 1 position. After "age" and depth adjustment, they were arithmetically averaged and yielding 1745 psia at $3609 \mathrm{ft}(1100 \mathrm{~m})$. It is named as an initial comingled pressure. Prediction of current data were calculated using ratio rule approximation as expressed in Eq. 12-13.

$$
\begin{aligned}
\left(\frac{\bar{p}_{\text {init }}}{\bar{p}_{\text {current }}}\right)_{\text {all }} & =\left(\frac{\bar{p}_{\text {init }}}{\bar{p}_{\text {current }}}\right)_{i-\text { th layer }} \\
\left(\frac{J_{\text {init }}}{J_{\text {current }}}\right)_{\text {all }} & =\left(\frac{J_{\text {init }}}{J_{\text {current }}}\right)_{\text {i-th layer }}
\end{aligned}
$$

Calculated current layer pressure are 1655 psia, 1605 psia and 1975 psia for layer 1, 2, and 3 respectively. The each layer productivity index themselves were arithmetically computed using Eq. 13 from all data with respect to what layer was being calculated (See Table 4). The reservoir is set at $0.85 \mathrm{~g} / \mathrm{cc}$ of oil density, $1.13 \mathrm{~g} / \mathrm{cc}$ of brine within 0.98 water cut.

Table 4. Final pressure and productivity index calculation.

\begin{tabular}{|ccccc|}
\hline \multirow{2}{*}{ Layer } & \multicolumn{2}{c}{$\begin{array}{c}\text { Reservoir pressure [psia] } \\
\text { at 3609 } \mathrm{ft}(1100 \mathrm{~m})\end{array}$} & \multicolumn{2}{c|}{ [stb/d/psia] } \\
\cline { 2 - 5 } & Initial & Current & Initial & Current \\
\hline 1 & 1779 & 1655 & 1.098 & 1.039 \\
2 & 1725 & 1605 & 3.430 & 3.246 \\
3 & 2122 & 1975 & 0.433 & 0.409 \\
All comingled & 1875 & 1745 & 1.654 & 1.565 \\
\hline
\end{tabular}


Data of reservoir derived from finite-difference based model confirms that the algorithm also works well with respect to the common tool in the industry as compared in Table 5. It shows the computation is easy to execute.

Table 5. Comparison study from finite-difference data model versus common software in market.

\begin{tabular}{|c|c|c|c|c|c|}
\hline \multirow{2}{*}{ Layer } & \multirow{2}{*}{$\begin{array}{l}P_{w f} \\
{[\text { psia] }}\end{array}$} & \multirow{2}{*}{$\begin{array}{l}P_{\text {res }} \\
\text { [psia] }\end{array}$} & \multicolumn{2}{|c|}{$\begin{array}{l}\text { Flow rate from all layers } \\
\qquad[\mathrm{stb} / \mathrm{d}]\end{array}$} & \multirow{2}{*}{$\begin{array}{l}\text { Relative error [ ] } \\
\frac{|X-Y|}{Y} \times 100 \%\end{array}$} \\
\hline & & & $\begin{array}{c}\text { Analytical } \\
\text { program, } X\end{array}$ & $\begin{array}{l}\text { Commercial } \\
\text { software, } Y\end{array}$ & \\
\hline 1 & 1572 & 1655 & 0 & 0 & - \\
\hline 2 & 1412 & 1605 & 973 & 954 & 2.02 \\
\hline \multirow[t]{2}{*}{3} & 1092 & 1975 & 129 & 130 & 0.98 \\
\hline & & Total & 1102 & 1084 & 1.66 \\
\hline
\end{tabular}

Therefore, it is critical to set the ISC where the highest gain is aimed. Table 6 suggests that the bottom group consist of layer 1 and 2 and the upper group is only layer 3 . This case serves the highest liquid rate at $1677 \mathrm{stb} / \mathrm{d}$. The most influencial factor is at layer 2 where it has the least reservoir pressure at 1605 psia. It may be encountered by crossflow if it is not well assisted by supplying the lest flowing bottom hole pressure.

Table 6. Optimisation study of the ISC setting depth using 3 inch casing ID and 0.25 inch choke size (ID).

\begin{tabular}{|cccccc|}
\hline Position of ISC is & $P_{w f}$ & \multicolumn{3}{c}{ Liquid rate [stb/d] } & Total liquid \\
at (above slightly) & {$[\mathrm{psia}]$} & 1 & 2 & 3 & 1867 \\
\hline 1 & 1429 & 31 & 1450 & 186 & 1667 \\
2 & 1429 & 31 & 1459 & 187 & 1677 \\
\hline
\end{tabular}

\section{Concluding Remarks}

A mathematical-based solution has been developed to conduct production performance on multilayer well. The model has been coded into macro-excel program. The vital input data into the program are the IPR parameters (pressure reservoir and PI) that could be obtained using test data per layer production. The output is clear covering each layer rate and flowing well pressure which are helpful to determine which layer that is flowing or having problem (crossflow).

The analysis to increase production from multilayer by implementing a tool that has a purpose like a vacuum is modeled by a nozzle-type choke equation. By inputting the rate and pressure drop across the choke, the diameter size (size of ISC) could be calculated and vice versa.

A limited data has been overcome by implementing ratio rule approximation with respect to time dimension: current and initial, and data dimension: each layer or entire reservoir. The validation through hypothetical data has been conducted and shows a good agreement with the model.

It is a vital to test a well productivity in a single layer reservoir mode hence there will be accurate data consist of PI, reservoir pressure, and rate to predict and evaluate the multilayer well production performance. 


\section{Nomenclature}

$\begin{array}{rll}q_{i} & : & \text { Liquid flow rate from } i \text {-th layer, stb/d } \\ J_{i} & : & \text { Reservoir Productivity Index PI of } i \text {-th layer, stb/d/psia } \\ \bar{p}_{i} & : & \text { Average of } i \text {-th comingled or single reservoir pressure, psia } \\ p_{w f} & : & \text { Flowing bottom hole pressure, psia } \\ C_{D} & : & \text { Nozzle-type choke constant } \\ d_{2} & : & \text { Tubing inner diameter, inch } \\ d_{1} & : & \text { Choke inner diameter, inch } \\ N_{R e} & : & \text { Reynold's number } \\ \bar{\rho} & : & \text { Average density, lbm/cuft } \\ \bar{\mu} & : & \text { Average liquid viscosity, cP } \\ p_{I N} & : & \text { Inlet pressure from bottom layer, psia } \\ p_{\text {OUT }}, p_{\text {disc }} & : & \text { Outlet or discharge pressure to upper layer, psia }\end{array}$

\section{References}

H. Park and R.N. Horne. 1989. Well test analysis of a multilayered reservoir with formation crossflow. SPE-19800-MS. SPE Annual Technical Conference and Exhibition, 8-11 October, San Antonio, Texas. DOI: 10.2118/19800-MS

M. Jalali et al. 2016. Cross-flow analysis of injection wells in a multilayered reservoir. Petroleum 2(3): 273-281. DOI: 10.1016/j.petlm.2016.05.005

F.A. Happy, M.S. Hossain, and A. Rahman. 2014. Pressure data analysis and multilayer modeling of a gas-condansate reservoir. Asia Pacific J Energy and Enviro 1(2): 172-182.

Y. Mao and M. Zeidouni. 2017. Temperature transient analysis for characterization of multilayer reservoirs with crossflow. SPE-185654-MS. SPE Western Regional Meeting, 23-27 April, Bakersfield, California. DOI: 10.2118/185654-MS

P. Permadi, W. Wibowo, A.K. Permadi. 1998. Inflow performance of a stacked multilateral well. SPE39750-MS. SPE Asia Pacific Conference on Integrated Modelling for Asset Management, 2324 March, Kuala Lumpur, Malaysia. DOI: 10.2118/39750-MS

B. Guo, A. Ghalambor, and K. Ling. 2008. A rigorous composite-inflow-performance relationship model for multilateral wells. SPE Production \& Operation 3(2): 241-248. DOI: 10.2118/100923-PA.

M.A. Zarea and D. Zhu. 2011. An integrated performance model for multilateral wells equipped with inflow control valves. SPE-142373-MS. SPE EUROPEC/EAGE Annual Conference and Exhibition, 23-26 May, Vienna, Austria. DOI: 10.2118/142373-MS

Ayesha et al. 2010. Wellbore segmentation using Inflow Control Devices: Design \& optimization process. SPE-137992-MS. Abu Dhabi International Petroleum Exhibition and Conference, 1-4 November, Abu Dhabi, UAE. DOI: 10.2118/137992-MS

K.E. Brown. 1984. The technology of artificial lift methods: Volume 4, production optimization of oil and gas wells by nodal systems analysis. Tulsa, Oklahoma: PennWell Books.

B. Guo, W.C. Lyon, and A. Ghalambor. 2007. Petroleum production engineering: A computer assisted approach. Elsevier Science \& Technology Books. 